\title{
Pengaruh Kecepatan Potong, Kecepatan Pemakanan Dan Sudut Potong Utama Terhadap Kekasaran Permukaan Pada Proses Bubut Medium Carbon Steel
}

\author{
P. I. Gultom ${ }^{1}$, Kiswandono ${ }^{2}$ \\ ${ }^{1}$ Jurusan Teknik Mesin DIII, FTI, ITN Malang \\ ${ }^{2}$ Jurusan Teknik Industri, FTI, ITN Malang \\ Email: peniel immanuel@yahoo.com
}

\begin{abstract}
Persaingan di industri manufaktur menuntut produk dengan kualitas tinggi dan produktivitas tinggi juga. Parameter pemesinan seperti sudut potong, kecepatan potong dan kecepatan pemakanan menentukan besarnya laju pengerjaan material atau material removal rate (MRR) dari proses bubut. Penentuan parameter pemesinan secara berlebihan justru akan menurunkan produktivitas karena adanya suatu produk yang harus dikerjakan ulang (reworked).

Penelitian ini khususnya akan ditekankan pada proses bubut dengan benda kerja medium carbon steel. Permasalahan yang timbul adalah bagaimana menentukan kecepatan potong, kecepatan pemakanan, dan sudut potong utama pada proses bubut dengan benda kerja medium carbon steel yang akan menghasilkan kehalusan permukaan hasil bubut pada produk.

Hasil dari penelitian menunjukkan bahwa proses bubut baja ST-60 tanpa follower rest, dengan parameter pemesinan sudut potong utama $\mathrm{Kr}=45^{\circ}$, kecepatan potong $60,5 \mathrm{~m} /$ menit, kecepatan pemakanan $44,66 \mathrm{~mm} / \mathrm{menit}$ dan pada kedalaman potong $0,2 \mathrm{~mm}$ diperoleh nilai kekasaran permukaan 3,72 $\mu \mathrm{m}$ atau tingkat kekasaran N8. Sedangkan untuk parameter pemesinan sudut potong utama $\mathrm{Kr}=90^{\circ}$, kecepatan potong $60,5 \mathrm{~m} / \mathrm{menit}$, kecepatan pemakanan 22,33 $\mathrm{mm} /$ menit dan pada kedalaman potong $0,2 \mathrm{~mm}$ diperoleh nilai kekasaran permukaan 3,69 $\mu \mathrm{m}$ atau tingkat kekasaran $\mathrm{N} 8$.
\end{abstract}

Keywords kecepatan potong, kecepatan pemakanan, sudut potong utama, medium carbon steel.

Paper type Research paper

\section{PENDAHULUAN}

Mesin perkakas sangat berperan penting dalam industri manufaktur. Umumnya mesin-mesin ini banyak digunakan dalam pengadaan atau reparasi komponen mesin. Dari beberapa mesin perkakas yang ada salah satunya adalah mesin bubut. Mesin bubut merupakan mesin perkakas konvensional yang digunakan untuk proses pemotongan logam (metal cutting process) dimana benda kerja yang berputar dicekam oleh chuck pada spindel utama dan pahat yang bergerak linear dicekam pada dudukan pahat (tool post).

Parameter pemesinan seperti kecepatan potong, kecepatan pemakanan, dan sudut potong utama menentukan besarnya laju pengerjaan material atau material removal rate (MRR) dari proses bubut. Penentuan sudut potong utama, kecepatan pemakanan, dan kecepatan pemakanan secara berlebihan justru akan menurunkan produktivitas karena adanya suatu produk yang harus dikerjakan ulang (reworked) bahkan diganti karena terjadinya cacat pada permukaan hasil pemotongan.

Kekasaran permukaan didefinisikan sebagai ketidakteraturan konfigurasi permukaan pada suatu benda atau bidang (Rochim, 1993). Hal ini terjadi karena terjadinya berbagai penyimpangan selama proses pemesinan, sehingga permukaan yang mempunyai bentuk sempurna tidak dapat dibuat.

Permukaan benda kerja memiliki nilai kekasaran permukaan tertentu, sesuai dengan ketentuan dari penggunaan benda kerja tersebut. Surftest Mitutoyo SJ - 301 digunakan sebagai alat ukur kekasaran permukaan. Peralatan ini dilengkapi dengan stylus dan penyangga yang dipasang pada posisi horisontal.

Farokhi, dkk [2] dalam penelitiannya mengenai pengaruh kecepatan putar spindle (Rpm) dan jenis sudut pahat pada proses pembubutan terhadap tingkat kekasaran benda kerja baja Ems 45 menyatakan bahwa semakin lancip sudut pahat maka nilai kekasaran permukaan semakin rendah. Variasi kecepatan spindle yang digunakan yaitu $2000 \mathrm{rpm}, 2250 \mathrm{rpm}$, $2500 \mathrm{rpm}, 2750 \mathrm{rpm}$, dan $3000 \mathrm{rpm}$. Sedangkan sudut pahat yang di variasikan yaitu sudut $35^{\circ}$, sudut $55^{\circ}$, dan sudut $80^{\circ}$.

Saputra dan Wulandari [6] melakukan penelitian tentang perbandingan tingkat kekasaran dan getaran pahat pada pemotongan orthogonal dan oblique akibat sudut potong pahat menunjukkan bahwa tingkat kekasaran permukaan yang paling baik terdapat pada sudut potong $70^{\circ}$ masing-masing dengan nilai kekasaran 1,47 $\mu \mathrm{m}$ dan $1,91 \mu \mathrm{m}$. Untuk nilai kekasaran tertinggi terdapat pada sudut potong $90^{\circ}$ masing-masing dengan nilai kekasaran $3,32 \mu \mathrm{m}$ dan $3,76 \mu \mathrm{m}$. Sedangkan untuk nilai getaran yang paling baik terdapat pada sudut potong $70^{\circ}$ masing-masing dengan nilai getaran 0,86 $\mathrm{mm} / \mathrm{s}$ dan $0,98 \mathrm{~mm} / \mathrm{s}$, untuk nilai getaran yang paling tinggi terdapat pada sudut potong $90^{\circ}$ masing-masing dengan nilai 
getaran $1,26 \mathrm{~mm} / \mathrm{s}$ dan $1,31 \mathrm{~mm} / \mathrm{s}$. Sehingga dapat disimpulkan bahwa sudut potong yang paling baik yang menghasilkan nilai kekasaran dan getaran paling baik (rendah) adalah sudut potong $70^{\circ}$ baik orthogonal maupun oblique.

Penelitian ini khususnya akan ditekankan pada proses bubut dengan benda kerja Medium Carbon Steel. Adapun tujuan penelitian ini menentukan sudut potong utama, kecepatan potong dan kecepatan pemakanan pada proses bubut dengan benda kerja Medium Carbon Steel yang akan menghasilkan kehalusan permukaan benda kerja. Luaran yang diperoleh merupakan parameter proses pembubutan Medium Carbon Steel untuk finishing.

\section{METODE PENELITIAN}

Langkah-langkah atau tahapan penelitian yang digunakan adalah sebagai berikut:

- Survey lapangan. Studi lapangan dilakukan untuk mengamati proses bubut medium carbon steel yang digunakan sebagai bahan pertimbangan dalam memodifikasinya

- Studi Literatur. Tujuan studi literatur ini adalah untuk menemukan gap research dari penelitian sejenis sebelumnya. Sumber bacaan dapat berupa buku tesis, jurnal dan buku teks.

- Rumusan masalah

- Uji Pemotongan. Pemotongan dilakukan dengan menggunakan tail stock. Tujuannya adalah untuk mendapatkan hasil permukaan benda kerja pada masing-masing kondisi pemotongan.

- Pengukuran Kekasaran Permukaan. Untuk mendapatkan angka kekasaran dilakukan pengukuran kekasaran permukaan pada masing-masing kondisi pemotongan

- Analisis Data. Data yang diperoleh dianalisis dengan bantuan software untuk mengetahui kondisi pemotongan.

- Kesimpulan dan Saran.

Data yang digunakan pada penelitian ini adalah merupakan data primer yang diperoleh dari hasil percobaan. Variabel yang digunakan pada penelitian ini adalah sebagai berikut:

Variabel Proses

- Putaran mesin $638 \mathrm{rpm}$ dan $520 \mathrm{rpm}$

- Sudut potong $90^{\circ}$ dan $45^{\circ}$

- Gerak makan $0,07 \mathrm{~mm} /$ put dan $0,035 \mathrm{~mm} /$ put

Variabel Respons

- $\quad$ Angka kekasaran Permukaan dengan kedalaman potong 0,2 mm.

\section{Variabel Konstan}

- Variabel konstan yang didasarkan pada parameter proses pemotongan dengan menggunakan pahat insert jenis carbide TCMT 16T304 dimana material benda kerja medium carbon steel ST-60.

\section{HASIL DAN PEMBAHASAN}

\section{Uji Pemotongan dengan Mesin Bubut}

Uji pemotongan dengan proses bubut merupakan suatu pengujian yang dilakukan untuk mengetahui seberapa besar kekasaran permukaan dalam suatu proses pemotongan. Uji pemotongan pada percobaan ini dilakukan menjadi 2 kondisi yaitu sudut potong utama $\mathrm{Kr}=45^{\circ}$ dan sudut potong utama $\mathrm{Kr}=90^{\circ}$.

Efek regeneratif yang terjadi antara pahat dan benda kerja saat proses pemotongan mengakibatkan proses bubut menjadi tidak stabil dimana sistem tidak mampu menahan getaran (chatter) yang terjadi.

Kedalaman potong yang digunakan dalam percobaan ini sebesar 0,2 $\mathrm{mm}$. Terjadinya chatter ditandai dengan timbulnya suara bising yang berlebihan dan meningkatnya kekasaran permukaan hasil pemotongan. Mesin bubut yang digunakan dalam penelitian ini adalah LA 530 x 1100 seperti pada Fig 1.

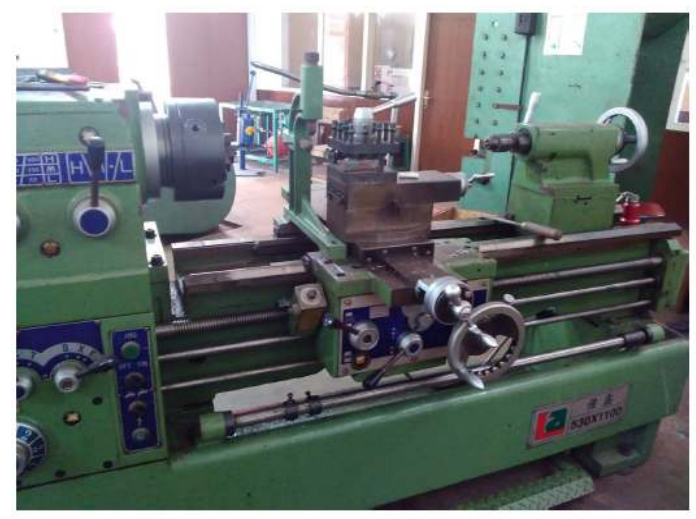

Fig. 1. Mesin Bubut LA 530 x 1100. 


\section{Uji Pemotongan Dengan Sudut Potong Utama Kr $=45^{\circ}$}

Gambar hasil pemotongan baja ST-60 dengan menggunakan pahat potong carbide insert dimana sudut potong utama $\mathrm{Kr}=45^{\circ}$ ditunjukkan pada Fig 2 dan Fig 3. Parameter proses pembubutan yang digunakan putaran mesin $638 \mathrm{rpm}$, kedalaman potong $0,2 \mathrm{~mm}$.

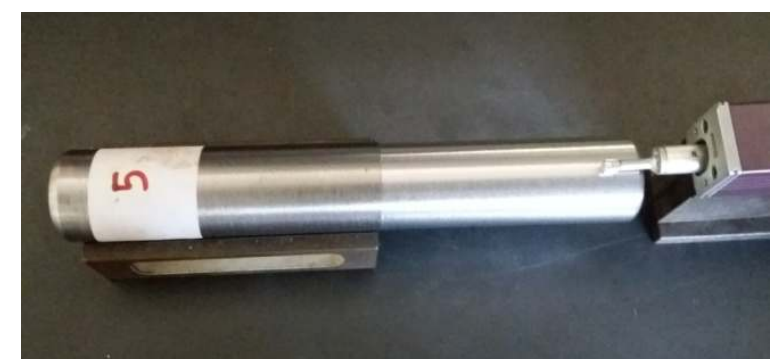

Fig. 2. Hasil pemotongan dengan gerak makan $0,07 \mathrm{~mm} /$ putaran

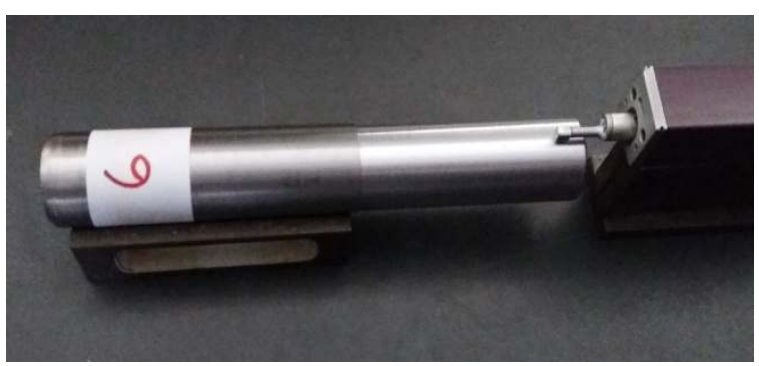

Fig. 3. Hasil pemotongan dengan gerak makan $0,035 \mathrm{~mm} /$ putaran

Gambar hasil pemotongan baja ST-60 dengan menggunakan pahat potong carbide insert dimana sudut potong utama $\mathrm{Kr}=45^{\circ}$ ditunjukkan pada Fig 4 dan 5. Parameter proses pembubutan yang digunakan putaran mesin $520 \mathrm{rpm}$, kedalaman potong $0,2 \mathrm{~mm}$.

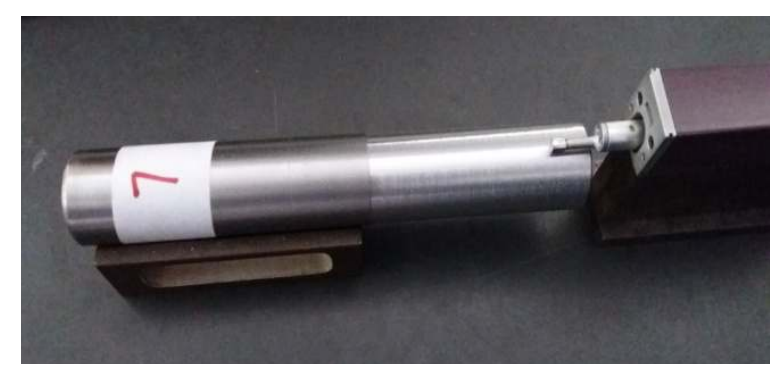

Fig. 4. Hasil pemotongan dengan gerak makan $0,07 \mathrm{~mm} /$ putaran

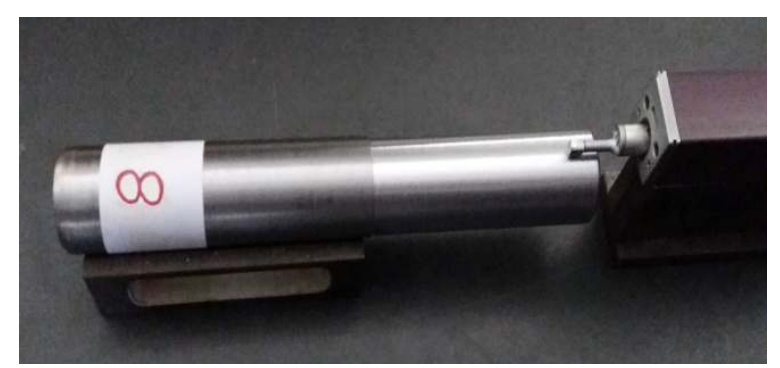

Fig. 5. Hasil pemotongan dengan gerak makan $0,035 \mathrm{~mm} /$ putaran 


\section{Uji Pemotongan Dengan Sudut Potong Utama Kr $=90^{\circ}$}

Gambar hasil pemotongan baja ST-60 dengan menggunakan pahat potong carbide insert dimana sudut potong utama $\mathrm{Kr}=90^{\circ}$ ditunjukkan pada Fig 6 dan 7. Parameter proses pembubutan yang digunakan putaran mesin $638 \mathrm{rpm}$, kedalaman potong $0,2 \mathrm{~mm}$.

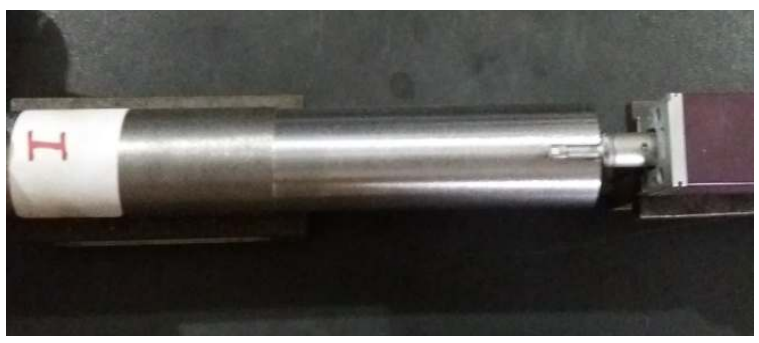

Fig. 6. Hasil pemotongan dengan gerak makan $0,07 \mathrm{~mm} /$ putaran

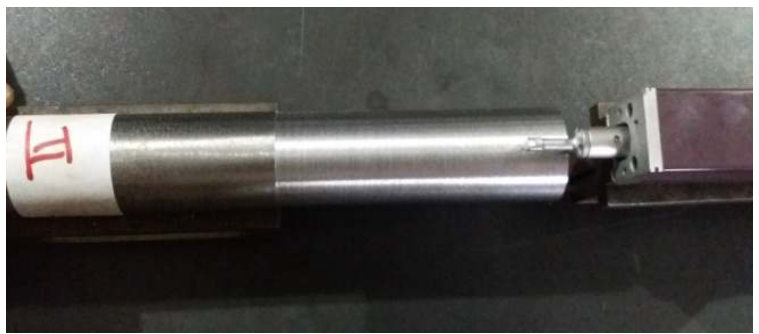

Fig. 7. Hasil pemotongan dengan gerak makan $0,035 \mathrm{~mm} /$ putaran

Gambar hasil pemotongan baja ST-60 dengan menggunakan pahat potong carbide insert dimana sudut potong utama $\mathrm{Kr}=90^{\circ}$ ditunjukkan pada gambar 8 dan gambar 9. Parameter proses pembubutan yang digunakan putaran mesin $520 \mathrm{rpm}$, kedalaman potong $0,2 \mathrm{~mm}$.

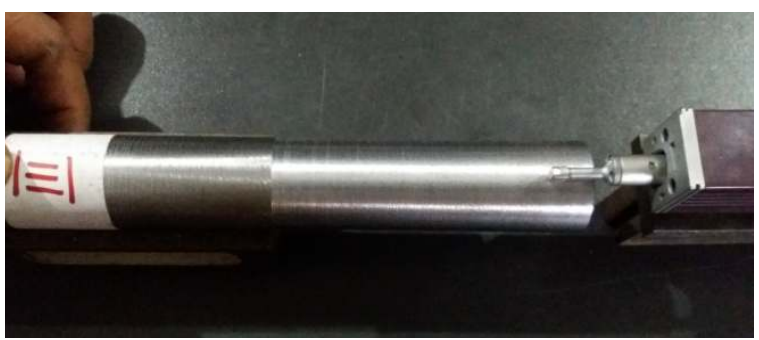

Fig. 8. Hasil pemotongan dengan gerak makan $0,07 \mathrm{~mm} /$ putaran

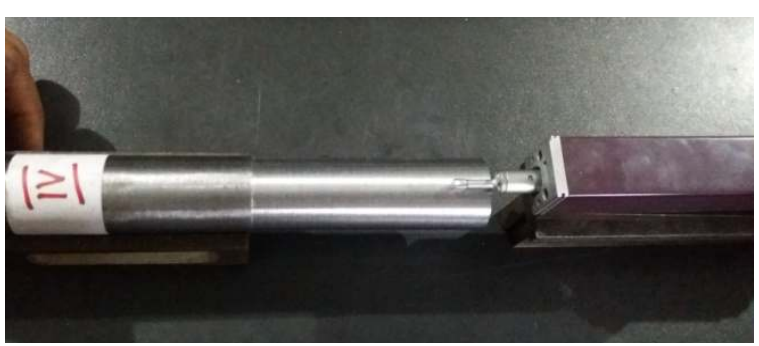

Fig. 9. Hasil pemotongan dengan gerak makan $0,035 \mathrm{~mm} /$ putaran

\section{Pembahasan}

Pengukuran data kekasaran permukaan didapat dengan mengukur permukaan setelah dilakukan proses gerinda permukaan dengan menggunakan surftest SJ-301, dengan tingkat ketelilitan 0,01 mikron. Sebelum dilakukan pengukuran, benda kerja dibersihkan terlebih dahulu, kemudian diukur dengan arah tegak lurus pembubutan sebanyak 3 titik sampel. Kemudian ditentukan data maksimum dari hasil pengukuran kekasaran tersebut sebagai nilai kekasaran permukaan. 
Pengaruh Kecepatan Potong, Kecepatan Pemakanan Dan Sudut Potong Utama Terhadap Kekasaran Permukaan Pada Proses Bubut Medium Carbon Steel

Adapun data hasil pengukuran kekasaran permukaan baja ST-60 dapat dilihat pada tabel 1 dan tabel 2 berikut.

\begin{tabular}{cccc} 
TABLE I. & HASIL PENGUKURAN NILAI KEKASARAN PERMUKAAN KR $=45^{\circ}$ \\
\hline $\begin{array}{c}\text { Putaran } \\
\begin{array}{c}\text { Mesin } \\
(\mathrm{rpm})\end{array}\end{array}$ & $\begin{array}{c}\text { Gerak makan } \\
(\mathrm{mm} / \text { putaran })\end{array}$ & $\begin{array}{c}\text { Kedalaman } \\
\text { potong } \\
(\mathrm{mm})\end{array}$ & $\mathrm{Ra}(\mu \mathrm{m})$ \\
\hline 638 & 0,07 & & 3,72 \\
638 & 0,035 & & 4,62 \\
520 & 0,07 & 5,03 \\
520 & 0,35 & & 4,5 \\
\hline
\end{tabular}

TABLE II. HASIL PENGUKURAN NILAI KEKASARAN PERMUKAAN KR $=90^{\circ}$

\begin{tabular}{cccc}
\hline $\begin{array}{c}\text { Putaran } \\
\text { Mesin } \\
(\mathrm{rpm})\end{array}$ & $\begin{array}{c}\text { Gerak makan } \\
(\mathrm{mm} / \text { putaran })\end{array}$ & $\begin{array}{c}\text { Kedalaman } \\
\text { potong } \\
(\mathrm{mm})\end{array}$ & $\mathrm{Ra}(\mu \mathrm{m})$ \\
\hline 638 & 0,07 & & 4,18 \\
638 & 0,035 & & 3,69 \\
520 & 0,07 & & 3,99 \\
520 & 0,35 & & 4,12 \\
\hline
\end{tabular}

Untuk tingkat kekasaran permukaan yang bisa dicapai pada pembubutan baja ST-60 tanpa menggunakan follower rest dengan kedalaman potong 0,2 mm adalah dari N8 sampai N9, dimana untuk tingkat kekasaran permukaan N8 adalah kategori normal dan untuk N9 kategori kasar. Berdasarkan hubungan kecepatan potong, kecepatan pemakanan dan sudut potong utama pahat terhadap tingkat kekasaran permukaan baja ST-60 Baja yang bisa dicapai oleh mesin bubut LA $530 \mathrm{x}$ 1100 terlihat pada Tabel 3 dan Tabel 4 berikut.

TABLE III. TINGKAT KEKASARAN PERMUKAAN BAJA ST-60 DENGAN SUDUT KR $=45^{\circ}$

\begin{tabular}{cccc}
\hline $\begin{array}{c}\text { Kecepatan } \\
\text { Potong } \\
(\mathrm{m} / \text { menit })\end{array}$ & $\begin{array}{c}\text { Kecepatan } \\
\text { Pemakanan } \\
(\mathrm{mm} / \text { menit })\end{array}$ & $\begin{array}{c}\text { Kedalaman } \\
\text { potong } \\
(\mathrm{mm})\end{array}$ & $\begin{array}{c}\text { Tingkat } \\
\text { Kekasaran } \\
\text { Permukaan }\end{array}$ \\
\hline & 44,66 & & $\mathrm{~N} 8$ \\
& 22,33 & & $\mathrm{~N} 9$ \\
& 36,4 & & $\mathrm{~N} 9$ \\
& 18,2 & & $\mathrm{~N} 8$ \\
\hline
\end{tabular}

TABLE IV. TINGKAT KEKASARAN PERMUKAAN BAJA ST-60 DENGAN SUDUT KR $=90^{\circ}$

\begin{tabular}{cccc}
\hline $\begin{array}{c}\text { Kecepatan } \\
\text { Potong } \\
(\mathrm{m} / \text { menit })\end{array}$ & $\begin{array}{c}\text { Kecepatan } \\
\text { Pemakanan } \\
(\mathrm{mm} / \text { menit })\end{array}$ & $\begin{array}{c}\text { Kedalaman } \\
\text { potong } \\
(\mathrm{mm})\end{array}$ & $\begin{array}{c}\text { Tingkat } \\
\text { Kekasaran } \\
\text { Permukaan }\end{array}$ \\
\hline & 44,66 & & $\mathrm{~N} 8$ \\
& 22,33 & & $\mathrm{~N} 8$ \\
& 36,4 & & $\mathrm{~N} 8$ \\
& 18,2 & & $\mathrm{~N} 8$ \\
\hline
\end{tabular}




\section{KESIMPULAN}

Berdasarkan pada hasil analisis dan pembahasan pada bab sebelumnya, dapat disimpulkan beberapa hal berkaitan dengan proses bubut baja ST-60 dengan dimensi $\varnothing 30 \mathrm{~mm}$ dan panjang $200 \mathrm{~mm}$.

- Pada proses bubut tanpa follower rest, dimana kedalaman potong 0,2 mm dengan sudut potong utama $\mathrm{Kr}=45^{\circ}$, kecepatan potong $60,5 \mathrm{~m} /$ menit dan kecepatan pemakanan $44,66 \mathrm{~mm} /$ menit diperoleh nilai kekasaran permukaan $3,72 \mu \mathrm{m}$ atau tingkat kekasaran $\mathrm{N} 8$.

- Pada proses bubut tanpa follower rest, dimana kedalaman potong $0,2 \mathrm{~mm}$ dengan sudut potong utama $\mathrm{Kr}=90^{\circ}$, kecepatan potong $60,5 \mathrm{~m} /$ menit dan kecepatan pemakanan $22,33 \mathrm{~mm} /$ menit diperoleh nilai kekasaran permukaan $3,69 \mu \mathrm{m}$ atau tingkat kekasaran N8.

\section{DAFTAR PUSTAKA}

[1] Cheng, C. C., Kuo, C. P., dan Cheng, W. N. (2009), "Moving Follower Rest Design Using Vibration Absorbers For Ball Screw Grinding," Journal of Sound and Vibration, Vol. 326, hal 123-136.

[2] Farokhi M., Sumbodo W., Rusiyanto (2017), Pengaruh Kecepatan Putar Spindle (Rpm) Dan Jenis Sudut Pahat Pada Proses Pembubutan Terhadap Tingkat Kekasaran Benda Kerja Baja Ems 45, Jurnal SAINTEKNO Vol. 15 No. 1 Juli 2017.

[3] Jianliang, dan Rongdi, Han (2006), “A United Model of Diametral Error in Slender Bar Turning with a Follower Rest," International Journal of Machine Tools \& Manufacture, Vol. 46, hal. 1002-1012.

[4] Kalpakjian, S. dan Schmid, S. R. (2001), Manufacturing Engineering and Technology, 4th edition, Prentice Hall, New York.

[5] Rochim, Taufiq (1993). Teori dan Teknologi Proses Pemesinan, Institut Teknologi Bandung, Bandung.

[6] Saputra E. D., Wulandari D. (2017), Perbandingan Tingkat Kekasaran Dan Getaran Pahat Pada Pemotongan Orthogonal Dan Oblique Akibat Sudut Potong Pahat, Jurnal Teknik Mesin Vol. 05 No. 02 Tahun 2017, Universitas Negeri Surabaya.

[7] Suhardjono (2000), Ein Variabel Einsetzbarer Gedämpfter Tilger zur Reduzierung von Ratterschwingungen bei Drehmaschinen, Wissenschaft \& Technik Verlag, Berlin. 